Research

\title{
Genetic commonality of macrolide-resistant group A beta hemolytic streptococcus pharyngeal strains
}

\author{
Angela L Myers*1, Mary Anne Jackson ${ }^{1}$, Rangaraj Selvarangan1, \\ Richard V Goering ${ }^{2}$ and Christopher Harrison ${ }^{1}$
}

\begin{abstract}
Address: ${ }^{1}$ Children's Mercy Hospitals and Clinics, University of Missouri-Kansas City School of Medicine, KC, MO, USA and ${ }^{2}$ Creighton University Medical Center School of Medicine, Omaha, NE, USA

Email: Angela L Myers* - amyers@cmh.edu; Mary Anne Jackson - mjackson@cmh.edu; Rangaraj Selvarangan - rselvarangan@cmh.edu; Richard V Goering - richardgoering@creighton.edu; Christopher Harrison - cjharrison@cmh.edu

* Corresponding author
\end{abstract}

This article is available from: http://www.ann-clinmicrob.com/content/8/I/33

(c) 2009 Myers et al; licensee BioMed Central Ltd.

This is an Open Access article distributed under the terms of the Creative Commons Attribution License (http://creativecommons.org/licenses/by/2.0), which permits unrestricted use, distribution, and reproduction in any medium, provided the original work is properly cited.

\begin{abstract}
Background: Group A beta hemolytic streptococcus (GABHS) pharyngitis is a common childhood illness. Penicillin remains the gold standard therapy, but macrolides are indicated for the penicillin allergic patient, and are often used for convenience.

Methods: We conducted a surveillance study of children with pharyngitis and positive streptococcal rapid antigen testing from 10/05 to 10/06 at 2 sites (A \& B). Demographics, treatment, and resistance data was collected and compared to previous data from 2002. Erythromycin (EM) resistance was determined by disk diffusion and E-test on 500 isolates. Pulse field gel electrophoresis (PFGE) was performed to measure genetic relatedness of isolates. StatXact version 8 software (Cytel Inc., Cambridge, MA) was utilized to perform Fisher's exact test and exact confidence interval $(\mathrm{Cl})$ analysis.

Results: There were no differences in resistance rates or demographic features, with the exception of race, between sites A \& B. EM resistance was 0 in 2002,3.5\% in 2005-06 at site A, and $4.5 \%$ in 2005-06 at site B. $3 / 7$ and $3 / 9$ had inducible resistance at $A$ and $B$ respectively. 8 isolates had relatedness $\geq 80 \%, 5$ of which were $88 \%$ homologous on PFGE.
\end{abstract}

Conclusion: Community macrolide resistance has increased following increased macrolide use. These results may have treatment implications if use continues to be high.

\section{Background}

Group A streptococcal pharyngitis (GABHS) is a common childhood infection that is most frequent in the school age child [1]. Antimicrobial therapy is pursued largely for the prevention of rheumatic fever, and organism eradication virtually eliminates this risk [2]. Penicillin is the gold standard therapy for GABHS infection, and penicillin resistance has never been documented [3]. Macrolides are recommended for the penicillin allergic patient. However, they are being increasingly used for convenience, due to once daily dosing, shorter course of therapy, and perhaps better taste. As macrolide use has increased, resistance has been noted with resultant bacteriologic failures [3-5].

There are two different macrolide resistance mechanisms that Group A streptococcus may carry. The first is an active 
efflux mechanism caused by the macrolide efflux gene, or mef A gene, which confers resistance to 14 and 15 membered macrolides, but not to 16 membered macrolides, lincosamides, or streptogramin b $[3,5]$. This is referred to as the $\mathrm{M}$ phenotype. The second is caused by erythromycin resistance methylase, or erm gene. The erm gene causes target site modification within the 50s ribosomal subunit. It is expressed in either an inducible or constitutive manner, which results in resistance to macrolides, lincosamides, and streptogramin b antibiotics [6].

Reports of macrolide resistance prevalence are varied from country to country throughout the world. Portugal has reported resistance rates of 27\%, Belgium 13\%, Spain $30 \%$, and Italy $40 \%$ [4,6-8]. While widespread macrolide resistance has been reported in several European countries, low level resistance has been predominantly reported in the US [9]. However, more recent studies have shown an increase in resistance rates to $6-7 \%$, with pockets of higher resistance at differing times between 10-20\% [10-12]. This increase in resistance has followed an increase in macrolide use on a national level [13]. Both inpatient and outpatient macrolide prescriptions increased in our institution by $11 \%$ and $15 \%$ respectively from 2002-04. Our study is an evaluation of local macrolide resistance in 2 separate clinical settings; an urban teaching hospital, and a community pediatric office, with comparison of local previous macrolide resistance data.

\section{Methods}

This was a prospective surveillance study of 400 children with positive rapid streptococcal antigen testing, and symptomatology consistent with streptococcal pharyngitis. A power calculation was performed and revealed that with a sample size of 400 we would have $90 \%$ power to detect a $10 \%$ shift in macrolide resistance prevalence from near zero to $10 \%$. Institutional review board approval was obtained.

Our urban teaching institution was designated as site A, and the community pediatric office was designated as site B. Convenience sampling of 8 specimens per week was obtained from each site from October 2005 to October 2006. Specimens were inoculated on Trypticase-Soy agar with 5\% sheep blood. (Remel Inc., Lenexa, KS) Isolates were confirmed to be GABHS by latex antigen agglutination. Susceptibility testing was performed by double disc (D- test) diffusion method, which allowed for identification of phenotype in resistant isolates [14]. D-testing was performed with a $2 \mu \mathrm{g}$ clindamycin disc and a $15 \mu \mathrm{g}$ erythromycin disc placed $12 \mathrm{~mm}$ apart, with subsequent evaluation for zone blunting around the clindamycin disc. Resistant isolates were then further tested to confirm minimum inhibitory concentration (MIC). Standard Clinical and Laboratory Standards Institute (CLSI) plating and susceptibility techniques were utilized, as well as breakpoints to determine resistance $[15,16]$. Baseline demographic characteristics including age, race, payor status, treatment, and zip codes were collected. Race was classified by parent report, and was included to characterize the patient population at each site.

Pulse field gel electrophoresis (PFGE) was performed on in situ Sfi1 digests of chromosomal DNA from all available resistant isolates using a CHEF DR III System (Bio-Rad, Hercules, CA) at $6 \mathrm{~V} / \mathrm{cm}, 14^{\circ} \mathrm{C}, 120^{\circ}$ included angle, with switching from 5 to $15 \mathrm{~s}$ for 10 hours, followed by switching from 15 to $60 \mathrm{~s}$ for 13 hours $[17,18]$. Sfi1 is a restriction enzyme that produces 5-7 well separated DNA fragments. [19]. Images of ethidium-bromide stained gels were archived using a Bio-Rad Gel Doc 1000 System. PFGE profiles were analyzed using BioNumerics v 4.01 (Applied Maths, St-Martens-Latern, Belgium). Isolates were given specific strain designations based on at least $80 \%$ similarity. In addition PFGE was performed on 2 susceptible isolates obtained within 2 weeks of each resistant isolate, in order to make direct genetic comparison of each resistant isolate to current circulating susceptible isolates. Comparison was made between site $\mathrm{A}$ and site $\mathrm{B}$, as well as previous site A data from 2002 using Fisher's exact test and exact confidence interval (CI) analysis. We used a two-sided alpha level of 0.05 and 95\% confidence limits throughout. These analyses used StatXact version 8 software (Cytel Inc., Cambridge, MA).

\section{Results}

Sites A and B showed no significant differences in demographic patient characteristics on age, sex, payor status, and treatment (Table 1). There was a difference in racial composition with 30\% white, 20\% Hispanic, 47\% African-American, $1 \%$ Asian, and $2 \%$ Other at Site A, and $80 \%$ white, $4 \%$ Hispanic, $7 \%$ African-American, $0 \%$ Asian, and $8 \%$ Other at Site B $(\mathrm{p}=0.0001)$.

There were a total of 16 resistant isolates, 7 from site A in 2005-2006 (3.5\%), and 9 from site B in 2005-2006 $(4.5 \%)$ (Table 2). There was no difference in resistance between the two sites ( $\mathrm{p}=0.80,95 \% \mathrm{CI}-0.20,0.31)$. No isolates with complete resistance were found at site $\mathrm{A}$ in

Table I: Demographic and Treatment Data

\begin{tabular}{lcc}
\hline & Site A & Site B \\
\hline Median/Mean age & 6 yrs/7.5 yrs & 6 yrs/7.5 yrs \\
Male & $104 / 200(52 \%)$ & $105 / 200(53 \%)$ \\
Caucasian & $61 / 200(30 \%)$ & $161 / 200(80 \%)$ \\
Medicaid & $131 / 200(65 \%)$ & $108 / 200(52 \%)$ \\
Penicillin/amoxicillin & $178 / 200(91 \%)$ & $179 / 200(90 \%)$ \\
Oral cephalosporin & $8 / 200(4 \%)$ & $20 / 200(10 \%)$ \\
Other/none & $14 / 200(7 \%)$ & $1 / 200(0.5 \%)$ \\
\hline
\end{tabular}


Table 2: Current GABHS Resistance Rates

\begin{tabular}{lll}
\hline & Site A & Site B \\
\hline Macrolide-Susceptible & $192 / 200(96 \%)$ & $188 / 200(94 \%)$ \\
Macrolide-Intermediate & $1 / 200(0.5 \%)$ & $3 / 200(1.5 \%)$ \\
Macrolide-Resistant $_{\text {Inducible Clindamycin Resistance }}{ }^{a}$ & $7 / 200(3.5 \%)$ & $9 / 200(4.5 \%)$ \\
\hline
\end{tabular}

a Determined by double disk diffusion (D-test)

2002, and the increase in resistance from 2002 to 20052006 at site A alone was not statistically significant ( $\mathrm{p}=$ $0.1,95 \%$ CI $-0.11,0.41)$. However, the combination of sites $A$ and $B$ revealed a statistically significant increase in resistance ( $p=0.05,95 \%$ CI $0.004,0.25)$. There were an additional 4 isolates with intermediate resistance noted in 2005-2006, 1 and 3 at site A and B respectively. There were two isolates with intermediate resistance noted in 2002.

D-zone testing revealed inducible clindamycin resistance, indicating erm phenotype, in $43 \%(3 / 7)$ of the isolates at site $\mathrm{A}$, and $33 \%$ (3/9) at site $\mathrm{B}$. (Table 2) Macrolide only resistance was found in the 10 remaining isolates, which denotes Mef A phenotype. MIC's for erm resistant strains were uniformly $>256 \mu \mathrm{g} / \mathrm{ml}$ and $12-32 \mu \mathrm{g} / \mathrm{ml}$ for the Mef A phenotype. Constitutive resistance was not found.

Seasonal differences in the resistance rate were evaluated by noting the number of resistant isolates found per month, and by dividing the year into 4 seasons. The seasons were divided into December, January and February for winter months, March, April, and May for spring months, June, July, and August for summer months, and September, October, and November for fall months. There were a small number of resistant isolates seen in the summer and fall seasons, with only 2 and 3 being noted respectively. However, an increase in the number of resistant isolates was seen in the winter and spring months at 4 and 7 respectively.

PFGE was initially performed with traditional SmaI restriction enzyme, commonly employed for analysis of Gram positive isolates. However, the macrolide resistant strains of the mef A phenotype were not cleaved, necessitating the use of Sfil enzyme on all isolates for PFGE analysis. [20] Twelve resistant isolates were available for PFGE performance. An additional 21 susceptible isolates underwent PFGE testing for comparison of potential clones. (Figure 1) Isolates were classified by site, week number of the study, and numbered 1-8 from the respective week. Eight of the 12 resistant isolates were found to have $\geq 80 \%$ homology, 6 of which were obtained from site B. (Figure 2) However, one of the patients who had a related strain isolated at site $\mathrm{A}$ lives within the site $\mathrm{B}$ zip code area. Five of the 8 isolates were in clusters with $\geq 88 \%$ homology, and 7 isolates were $\mathrm{D}$ zone test negative demonstrating $\mathrm{M}$ phenotype resistance. (Figure 2) We compared PFGE patterns of relatedness among resistance genes in relation to their geographic proximity within the zip code areas surrounding site $\mathrm{A}$ and site $\mathrm{B}$. There were no genetically related isolates from site A $(0 / 5)$, however 6 of the 7 $(85 \%)$ resistant isolates from site B that underwent PFGE had homology of $\geq 80 \%$.

\section{Discussion}

Macrolide resistance was found in our community, which represents a difference in findings from a previous analysis in 2002. Our rate of macrolide resistance was noted to be similar to rates reported nationally. Local resistance, MIC $\geq 1 \mu \mathrm{g} / \mathrm{ml}$, has increased from zero in 2002 to $4.5 \%$ in 2005-06, and has become apparent after a documented increase in macrolide use. This increase is not as significant as has been noted in other countries with high rates of macrolide use $[4,6-8,21,22]$. However, those countries had higher rates of macrolides use than is typically seen in the US, and therefore should be expected to have an elevated resistance rate that correlates with their use. Nevertheless, this data confirms that as rates of antibiotic use increase, resistance rates increase concomitantly. This data then underscores the importance of judicious antimicrobial use.

Nearly $40 \%$ of resistant isolates were D-zone test positive, which signifies clindamycin resistance in $1.5 \%$ of our GABHS isolates. Routine D-zone testing has not historically been part of GABHS testing, as GABHS is uniformly susceptible to penicillin, and typically requires no further workup past the speciation stage. However, a number of invasive GABHS infections occur yearly with a small percentage of deaths, which makes knowledge of susceptibilities of greater importance. Clindamycin has been utilized in the treatment of invasive infections thought to be caused by a toxin producing strain of GABHS for down regulation of toxin production [23-25]. This makes complete susceptibility testing an important feature when choosing therapy for infection. Although Kirby Bauer testing would provide knowledge of constitutive clindamycin resistance; it would provide no information regarding inducible clindamycin resistance. This information is important, as it may serve to alter the clinical care of the patient in the setting of invasive infection where the length of therapy is typically prolonged, raising the likelihood of inducible resistance resulting in treatment failures during the course of treatment.

Previous literature has reported difficulty in enzymatic degradation of Mef A resistant GAS isolates with SmaI enzyme [14]. We encountered the same difficulty, necessitating repeating PFGE testing with Sfil enzyme for all isolates. The inability of SmaI to degrade resistant isolates 


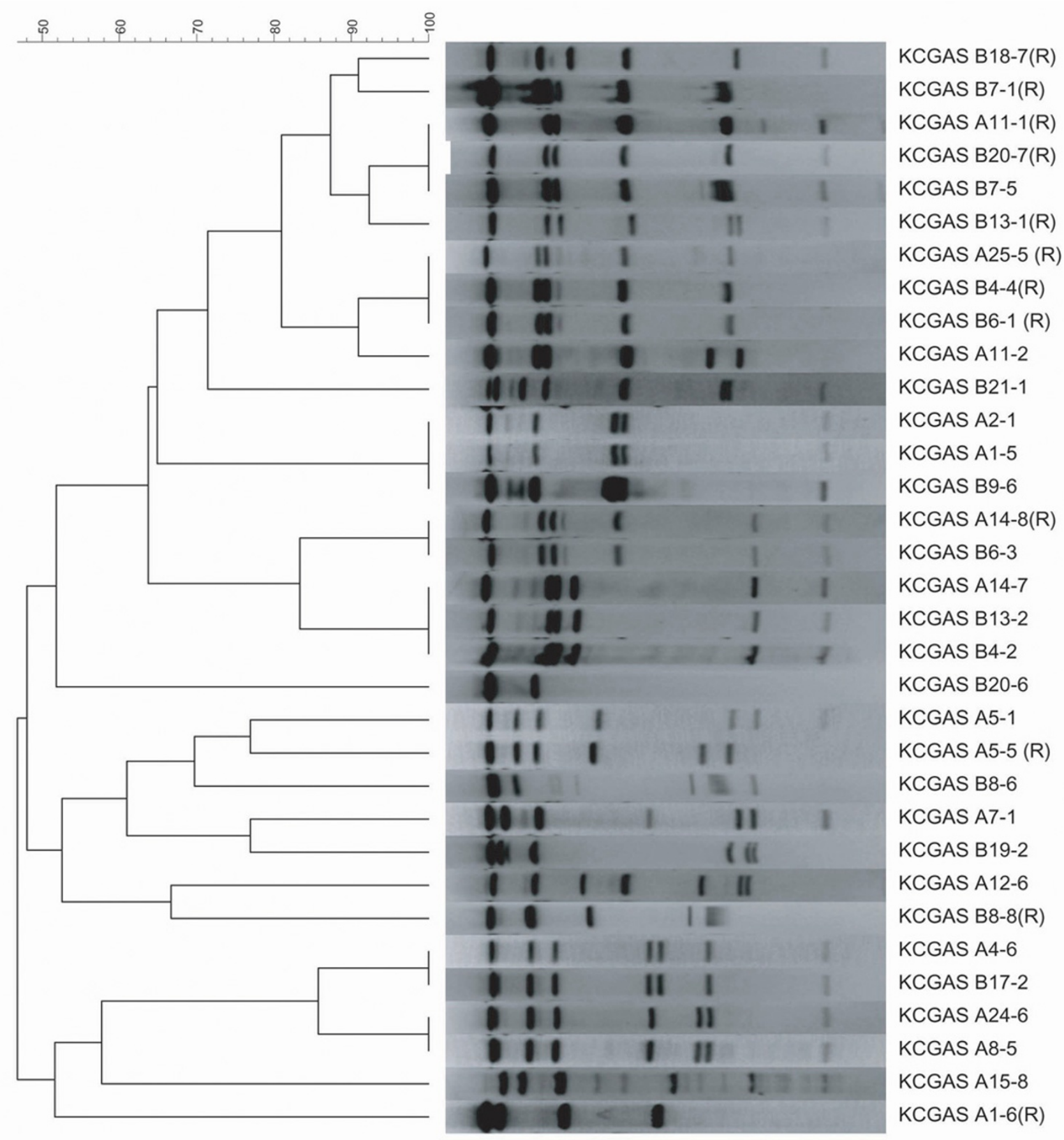

Figure I

PFGE of macrolide-resistant and susceptible Streptococcus pyogenes isolates. PFGE was performed on 2 susceptible isolates obtained within 2 weeks of each resistant isolate at the corresponding site for genetic comparison. Each isolate is identified by site of origin (A or B), week in which it was obtained (I-26), and the isolate number within the week (I-8). The dendogram, to the left, denotes the percent of genetic relatedness between resistant and susceptible isolates. The level at which the vertical line transect the horizontal line from the PFGE of each isolate determines its homology based on the percent scale above the dendogram. Twelve resistant and 21 susceptible isolates are pictured. Resistant isolates are identified as (R). 
PFGE

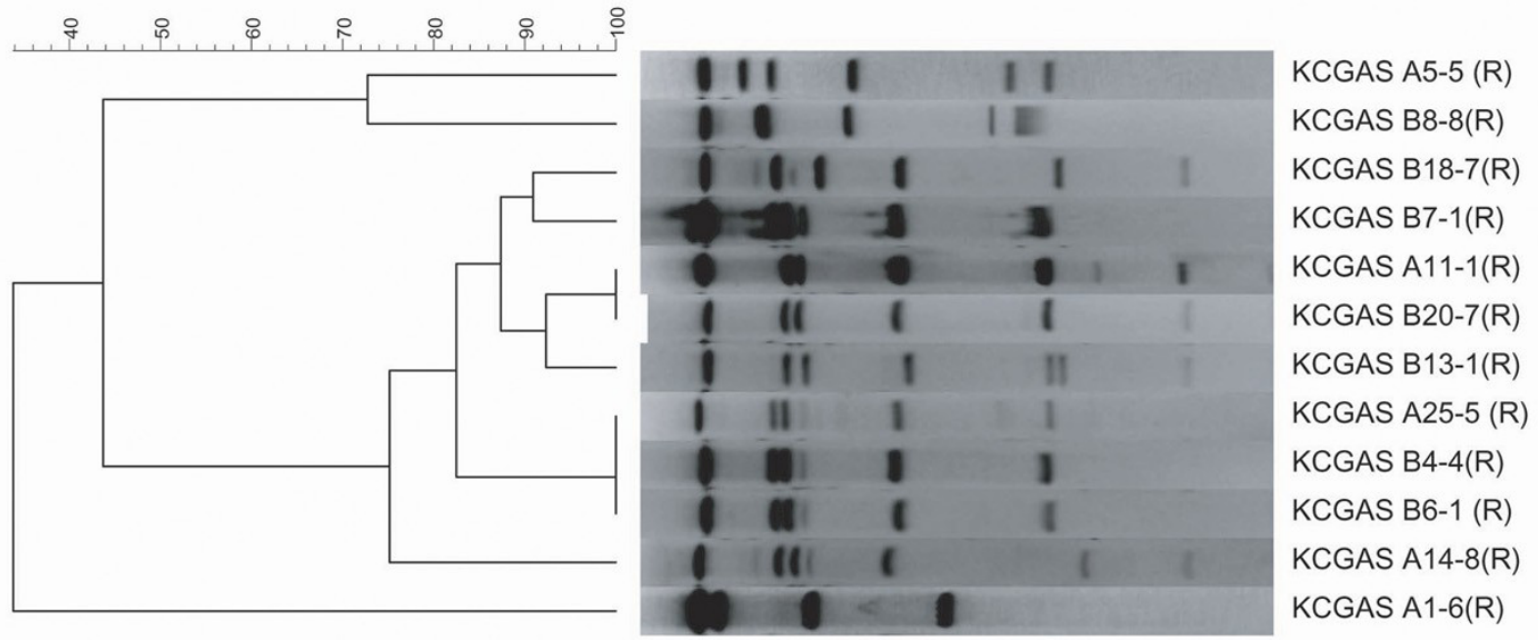

Figure 2

PFGE of macrolide-resistant S. pyogenes isolates. The dendogram, to the left, compares the percent of genetic relatedness among resistant isolates. The level at which the vertical line transect the horizontal line from the PFGE of each isolate determines its homology based on the percent scale above the dendogram. Twelve resistant isolates are pictured. Each isolate is identified by site of origin (A or B), week in which it was obtained (I-26), and the isolate number within the week (I-8). All isolates are identified as $(R)$ depicting their resistance.

has been theorized to be due to a modification within the genetic element that encodes the M-resistance phenotype [20]. Out of 5 resistant isolates, $4(\geq 80 \%)$ were found to be D-zone test negative which indicates $M$ phenotype of resistance. Resistance at site A was genetically diverse, but site B isolates were found to have more homology overall, with $6 / 7(85.6 \%)$ isolates revealing $\geq 80 \%$ similarity, indicating the likelihood of a single clone [19].

Although this was a large sample size, we detected a small number of resistant isolates, which limits the level of statistical precision. Still, our data reveal a trend in our local community that mirrors national resistance rates. Two distinct areas of the community were evaluated which allows for broader generalizations regarding resistance rates overall than would be reasonable if only one site participated in the study.

It was an interesting finding that site B had increased homology of the resistant isolates when compared to site A. This may be related to site B being a relatively smaller community than site A with the potential for easier spread of a single resistant clone. This theory would be better tested with comparison of several smaller community sites along with obtaining an adequate sample size to appropriately power the study.

\section{Conclusion}

Macrolide resistance has emerged in our local community, as well as on a national level. Although the overall percentages are not high at this point, it is becoming an increasingly important problem with continued high levels of macrolide use for upper respiratory tract infections. These results underscore the importance of identification of a bacterial infection prior to antibiotic use, with subsequent susceptibility testing on all invasive isolates.

\section{Abbreviations}

(GABHS): Group A Beta hemolytic Streptococcus; (EES): Erythromycin; (PFGE): Pulse Field Gel Electrophoresis; (MIC): Minimum Inhibitory Concentration; (D- zone test): Double disk diffusion; (CLSI): Clinical Laboratory Standards Institute; (CI): Confidence Interval; (mef): macrolide efflux; (erm): erythromycin resistance methylase.

\section{Competing interests}

The authors declare that they have no competing interests.

\section{Authors' contributions}

ALM developed the study concept, obtained IRB approval and grant funding, specimen collection, maintenance of database, PFGE of isolates, and manuscript preparation. 
MAJ aided in study design, grant writing, and manuscript preparation. RS helped with study design, carried out Etesting and D- testing in the microbiology lab, and participated in manuscript preparation. RVG supplied lab space and equipment, as well as aiding with carrying out of PFGE testing of isolates and interpretation of results. $\mathrm{CJH}$ helped with study design, statistical testing and interpretation, and manuscript preparation. All authors read and approved the final manuscript.

\section{Acknowledgements}

This study was funded by a Katherine Berry Richardson grant through Children's Mercy Hospitals \& Clinics. Pulse field gel electrophoresis was conducted and analyzed at Creighton University under the supervision of Richard V. Goering, PhD, Kristin K. Bonstetter, MS, and Daniel J. Wolter, $\mathrm{PhD}$. Specimen collection at site B was conducted by Michelle McIntosh, MD, and Trina Lamphear

\section{References}

I. Pickering LK, Baker CJ, Long SS, McMillan JA, ed: Red Book: 2006 Report of the Committee on Infectious Diseases. 27th edition. Elk Grove: American Academy of Pediatrics; 2006.

2. Chamovitz R, Catanzaro FJ, Stetson CA, Rammelkamp CH Jr: Prevention of rheumatic fever by treatment of previous streptococcal infections, evaluation of benzathine penicillin $\mathbf{G}$. $\mathrm{N}$ Engl J Med 1954, 25 I ( I 2):466-47I.

3. Syrogiannopoulos GA, Bozdogan B, Grivea IN, Ednie LM, Kritikou DI, Katopodis GD, Beratis NG, Applebaum PC: Two dosages of clarithromycin for five days, amoxicillin/clavulanate for five days or penicillin $\mathbf{V}$ for ten days in acute group $\mathbf{A}$ streptococcal tonsillopharyngitis. Pediatr Infect Dis J 2004, 23(9):857-865.

4. Schaad UB, Kellerhals $P$, Altwegg M: Azithromycin versus penicillin $\mathbf{V}$ for treatment of acute group $A$ streptococcal pharyngitis. Pediatr Infect Dis J 2002, 2 I (4):304-308.

5. Syrogiannopoulos GA, Grivea IN, Fitoussi F, Doit C, Katopodis GD, Bingen $E$, Beratis NG: High prevalence of erythromycin resistance of Streptococcus pyogenes in Greek children. Pediatr Infect Dis / 200I, 20(9):863-868.

6. Silva-Costa C, Ramirez M, Melo-Cristino J: Identification of macrolide-resistant clones of Streptococcus pyogenes in Portugal. Clin Microbiol Infect 2006, I 2(6):513-5I8.

7. Betriu C, Culebras E, Rodriguez-Avial I, Gomez M, Sanchez BA, Picazo J]: In vitro activities of tigecycline against erythromycin-resistant Streptococcus pyogenes and Streptococcus agalactiae: mechanisms of macrolide and tetracycline resistance. Antimicrob Agents Chemother 2004, 48(I):323-325.

8. Varaldo PE, Debbia EA, Nicoletti G, Pavesio D, Ripa S, Schito GC, Tempera G: Nationwide survey in Italy of treatment of Streptococcus pyogenes pharyngitis in children: influence of macrolide resistance on clinical and microbiological outcomes. Artemis-Italy Study Group. Clin Infect Dis 1999, 29(4):869-873.

9. Kaplan EL, Johnson DR, Del Rosario MC, Horn DL: Susceptibility of group A beta-hemolytic streptococci to thirteen antibiotics: examination of $30 \mathrm{I}$ strains isolated in the United States between 1994 and 1997. Pediatr Infect Dis J 1999 , | 8(1 2): 1069-1072.

10. Richter SS, Heilmann KP, Beekmann SE, Miller NJ, Miller AL, Rice CL, Doern CD, Reid SD, Doern GV: Macrolide-resistant Streptococcus pyogenes in the United States, 2002-2003. Clin Infect Dis 2005, 4 I(5):599-608.

II. Green MD, Beall B, Marcon MJ, Allen CH, Bradley JS, Dashefsky B, Gilsdorf JR, Schutze GE, Smith C, Walter EB, et al:: Multicentre surveillance of the prevalence and molecular epidemiology of macrolide resistance among pharyngeal isolates of group $A$ streptococci in the USA. J Antimicrob Chemother 2006, 57(6): $1240-1243$.

12. Martin JM, Green M, Barbadora KA, Wald ER: Erythromycinresistant group A streptococci in schoolchildren in Pittsburgh. N Engl J Med 2002, 346( (16): 1200-1206.
13. Stille CJ, Andrade SE, Huang SS, Nordin J, Raebel MA, Go AS, Chan $K A$, Finkelstein JA: Increased use of second-generation macrolide antibiotics for children in nine health plans in the United States. Pediatrics 2004, I | 4(5): | 206-12II.

14. Billal DS, Hotomi M, Yamauchi K, Fujihara K, Tamura S, Kuki K, Sugita R, Endou M, Mukaigawa J, Yamanaka N: Macrolide-resistant genes of Streptococcus pyogenes isolated from the upper respiratory tract by polymerase chain reaction. I Infect Chemother 2004, I 0(2): II I- I 20.

15. Institute CaLS: Performance standards for antimicrobial disk susceptibility tests. Approved Standards- 9th edition M2-A9 2006.

16. Institute CaLS: Performance Standards for Antimicrobial Susceptibility Testing. 16th Informational Supplement MI00-SI6 2006.

17. Murchan S, Kaufmann ME, Deplano A, de Ryck R, Struelens M, Zinn CE, Fussing V, Salmenlinna S, Vuopio-Varkila J, El Solh N, et al:: Harmonization of pulsed-field gel electrophoresis protocols for epidemiological typing of strains of methicillin-resistant Staphylococcus aureus: a single approach developed by consensus in 10 European laboratories and its application for tracing the spread of related strains. J Clin Microbiol 2003, 4I(4): I574-I585.

18. Pershing DH, Tenover FC, Versalovic Y, Tank B, Unger D, ed: Molecular Microbiology: Diagnostic Priniciples and Practice. Washington D.C.: ASM Press; 2004.

19. Musser JM, Kapur V, Szeto J, Pan X, Swanson DS, Martin DR: Genetic diversity and relationships among Streptococcus pyogenes strains expressing serotype MI protein: recent intercontinental spread of a subclone causing episodes of invasive disease. Infect Immun 1995, 63(3):994-1003.

20. Cocuzza CE, Mattina R, Mazzariol A, Orefici G, Rescaldani R, Primavera A, Bramati S, Masera G, Parizzi F, Cornaglia G, et al.: High incidence of erythromycin-resistant Streptococcus pyogenes in Monza (North Italy) in untreated children with symptoms of acute pharyngo-tonsillitis: an epidemiological and molecular study. Microb Drug Resist 1997, 3(4):37I-378.

21. Kao CH, Chen PY, Huang FL, Chen CW, Chi CS, Lin YH, Shih CY, Hu $\mathrm{BS}, \mathrm{Li} C \mathrm{CR}, \mathrm{Ma} J \mathrm{~S}$, et al.: Clinical and genetic analysis of invasive and non-invasive group $A$ streptococcal infections in central Taiwan. J Microbiol Immunol Infect 2005, 38(2): I05-III.

22. Szczypa K, Sadowy E, Izdebski R, Hryniewicz W: A rapid increase in macrolide resistance in Streptococcus pyogenes isolated in Poland during 1996-2002. I Antimicrob Chemother 2004, 54(4):828-83I.

23. Eneli I, Davies HD: Epidemiology and outcome of necrotizing fasciitis in children: an active surveillance study of the Canadian Paediatric Surveillance Program. J Pediatr 2007, I 5 I (I):79-84. e7 |

24. Sriskandan S, McKee A, Hall L, Cohen J: Comparative effects of clindamycin and ampicillin on superantigenic activity of Streptococcus pyogenes. J Antimicrob Chemother 1997, 40(2):275-277.

25. Zimbelman J, Palmer A, Todd J: Improved outcome of clindamycin compared with beta-lactam antibiotic treatment for invasive Streptococcus pyogenes infection. Pediatr Infect Dis J 1999, I 8( I 2): 1096-I I00.

Publish with Biomed Central and every scientist can read your work free of charge

"BioMed Central will be the most significant development for disseminating the results of biomedical research in our lifetime. "

Sir Paul Nurse, Cancer Research UK

Your research papers will be:

- available free of charge to the entire biomedical community

- peer reviewed and published immediately upon acceptance

- cited in PubMed and archived on PubMed Central

- yours - you keep the copyright 